\title{
ATIVIDADE ANTIFÚNGICA IN VITRO DE METABÓLITOS SECUNDÁRIOS PRODUZIDOS POR Bacillus cereus
}

Alan Garcia Cardoso da SILVA ${ }^{1}$

Tatiane Dias de SOUZA ${ }^{2}$

\begin{abstract}
${ }^{1}$ Farmacêutico e Químico, Doutorando em Química Analítica (UFBA) e Professor da Universidade Estadual de Feira de Santana - UEFS- alan.farma@ hotmail.com.

${ }^{2}$ Farmacêutica pela Universidade Estadual de Feira de Santana - UEFS e Licenciada em Química pela Universidade do estado da Bahia - UNEB - tati_d_s@gmail.com
\end{abstract}

Recebido em: 13/01/2016 - Aprovado em: 19/08/2016 - Disponibilizado em: 18/12/2016

\begin{abstract}
RESUMO:
Os antimicrobianos são amplamente utilizados, porém o uso indiscriminado tem aumentado o aparecimento de microrganismos resistentes produzindo infecções de difícil tratamento e cura. Sendo assim, a pesquisa de compostos químicos de fontes naturais surge como alternativa na busca de novas moléculas antimicrobianas. Com isso, o semiárido tornou-se alvo da comunidade científica e de empresas, principalmente indústria de medicamentos, devido a presença de uma alta taxa de biodiversidade. Neste estudo foi realizada uma coleta da rizosfera de plantas do gênero das Stachytarpheta em áreas definidas no município de Mucugê. Após a realização de um "screening" (Testes antifúngicos) de extratos de linhagens isoladas, foi selecionada uma linhagem identificada através do sequenciamento do DNA como Bacillus cereus. Observou-se uma atividade inibitória significativa dos extratos frente à Candida albicans, que através do bioautografia, visualizou-se que Rf 0,43 é a fração que obteve maior eficiência na inibição do patógeno. O estudo evidenciou uma importante etapa na pesquisa de um composto com atividade antimicrobiana, porém é necessária a realização de estudos mais minuciosos para alcançar maior ação frente ao patógeno analisado.
\end{abstract}

Palavras-chave: Antimicrobiano. Bioprospecção. Bioautografia. Bacillus cereus. Candida albicans.

\section{ANTIFUNGAL ACTIVITY IN VITRO SIDE METABOLITES PRODUCED BY Bacillus cereus}

\begin{abstract}
:
Antimicrobials are widely used, but indiscriminate use has increased the emergence of resistant microorganisms producing difficult to treat and cure infections. Therefore, the search of chemical compounds from natural sources is an alternative in the search for new antimicrobial molecules. Thus, the semi-arid became the target of the scientific community and companies, particularly the pharmaceutical industry, due to the presence of a high rate of biodiversity. This study we carried collection of rhizosphere of plants of the genus of Stachytarpheta in defined areas in the municipality of Mucugê. After conducting a "screening" (antifungal tests) of strains isolated extracts was selected a strain identified by DNA sequencing as Bacillus cereus. Observed a significant inhibitory activity of the extracts for Candida albicans, which by bioautography visualized Rf 0.43 fraction obtained is more efficient in inhibiting the pathogen. The study showed step important in the search of a compound with antimicrobial activity, but it is necessary to carry more detailed studies to achieve greater action against the pathogen analyzed.
\end{abstract}

Keywords: Antimicrobial. Bioprospecting. Bioautography. Bacillus cereus. Candida albicans.

\section{INTRODUÇÃO}

As infecções fúngicas sistêmicas têm aumentado de forma alarmante durante as últimas décadas, constituindo-se num dos problemas mais graves tanto do ponto de vista hospitalar quanto de saúde pública, um exemplo importante é o fungo Candida albicans e os dermatófitos (NARDIN et al, 
2006). O tratamento dessas infecções não tem se mostrado abrangente em sua totalidade pelo surgimento do crescente aumento de espécimes resistentes aos antifúngicos (TAKAHASHI; LUCAS, 2008; KHAN et al., 2009; KIRAZ; YASEMIN, 2011;). Desta forma, ressalta a importância de identificar e caracterizar novos compostos químicos que possibilite a obtenção de substancias capazes de controlar ou inibir o desenvolvimento dos fitopatógenos (SILVA et al., 2009)

Nesta busca incessante por drogas mais efetivas, os metabólitos oriundos de microrganismo apresentam substâncias com atividade farmacológica significativa, algumas das quais já serviram de base para a síntese de medicamentos. No período de 2000-2006, aproximadamente 50\% de moléculas químicas novas extraídas a partir de produtos naturais demonstraram a sua importância para o desenvolvimento de drogas no tratamento de doenças infecciosas (NEWMAN; CRAGG, 2007).

Nesse sentido, tem sido estudada a atividade antifúngica de várias classes de compostos químicos, naturais ou seus modelos sintéticos, como alcalóides, flavonóides, taninos, saponinas, diterpenos, cumarinas e imidas sobre fungos filamentosos e leveduras (PERRV; FOSTER, 1994; FAVEL et al., 1994; CECHINEL FILHO et $a l .$, 1996, LIMA et al, 2006; NAKAMURA et al, 2008; RAMASAMY K. et al, 2010, FERREIRA et al, 2012, XUE et al, 2012).
Em especial, destaca-se o gênero Bacillus spp. se como excelente agente de biocontrole maior prevalência devido a formação de endósporo e com grande versatilidade nos mecanismos de ação para driblar as defesas dos fitopatógenos (CAMPOS SILVA et al., 2008; LANNA FILHO; FERRO; PINHO, 2010; PAZ; 2010; LIMA et al., 2014).

Dentre os métodos de avaliação da atividade antimicrobiana destaca-se o método de difusão em placas (CELOTTO et al, 2003) e a bioautografia. Esta última é considerada uma técnica de fácil execução, precisão e baixo custo para identificação da atividade inibitória, frente a fungos ou bactérias, de um determinado componente. De acordo com Melo (2005), a bioautografia é considerada um ensaio eficiente e sensível na determinação da atividade antimicrobiana, pois menos de 2,5 $\mu \mathrm{g}$ da substância utilizada é suficiente para a formação do halo de inibição.

Entretanto, há necessidade de intensificar os estudos no semi-árido devido a vulnerabilidade climática da região, o Instituto Brasileiro de Geografia e Estatística (IBGE, 1994) afirmava que 54\% do bioma caatinga, com vegetação característica do semi-árido, encontrava-se em elevado estágio de antropização. Na velocidade em que ocorre o fenômeno de extinção de espécies, muitas plantas e animais com propriedades medicinais ou fontes potenciais de compostos 
bioativos correm o risco de desaparecer antes do seu valor ser reconhecido, o que torna ainda mais urgente intensificar os investimentos nesta área. Os fatos mencionados justificam o presente trabalho, cujo objetivo avaliar a atividade antifúngica de compostos extraídos do sobrenadante de Bacillus cereus isolados da rizosfera de plantas do gênero Stachytarpheta coletadas no semi-árido (no município de Mucugê/BA).

\section{MATERIAIS E MÉTODOS}

\section{Local de Coleta do solo rizosférico}

O campo em estudo delimitado neste trabalho é a região da Chapada Diamantina cidade de Mucugê, a escolha e amostragem de solos e plantas foram realizadas segundo os padrões internacionais de coleta, incluindo as coordenadas geográficas. Inicialmente, coletou-se as amostras de solo rizosférico de plantas da família Verbenaceae, gênero Stachytarpheta, em seguida essas amostras foram catalogadas, através de ficha de coleta, para posterior processamento.

\section{Isolamento, purificação e caracterização de}

\section{linhagens bacteriana}

O ensaio foi realizado no Laboratório

de Pesquisa em Microbiologia da Universidade Estadual de Feira de Santana. As amostras de solo da rizosfera, após uma diluição seriada, foram semeadas em meio específico para bactérias, e incubados à temperatura adequada. As placas contendo contagem de unidades formadoras de colônias (UFC) menores que 200 colônias foram utilizadas para o isolamento, tendo-se como critérios as características morfológicas e microscópicas distintas. As linhagens bacterianas foram selecionadas através de um "screening" (Testes antifúngicos) com os extratos obtidos a partir da cultura líquida. Em seguida, foram caracterizadas pelo método clássico de identificação através de Testes Morfológicos (forma, margem, cor, densidade, entre outros) e Testes Bioquímicos (Teste de Gram, catalase e citocromooxidase). Após os ensaios de avaliação da atividade fúngica, a linhagem selecionada foi submetida ao sequenciamento do gene $16 \mathrm{~S}$ rDNA para obter identificação da espécie.

\section{Obtenção de metabólitos secundários}

Para o crescimento em meio líquido, os microrganismos foram crescidos em um volume de $2000 \mathrm{~mL}$ de caldo nuriente, sob agitação, por $24 \mathrm{~h}$, à $28^{\circ} \mathrm{C}$. A partir do filtrado livre de células, obtido por centrifugação, procedeu-se o processo de extração com solvente orgânico. Nessa etapa, fez-se a extração dos metabólitos presentes no sobrenadante, com auxílio de um funil de separação, utilizando o acetato de etila, em seguida submeteu-se ao rotaevaporador.

\section{Avaliação da atividade antifúngica}


Para o estudo da atividade antifúngica do extrato extratos obtidos de culturas isoladas da rizosfera de plantas do gênero Stachytarpheta utilizou-se o teste de difusão em ágar (Pinto et al., 2003) e a bioautografia direta, métodos adaptados de Auer e Bettiol (1986) e Stangarlin et al. (1999). A utilização deste ensaio tem como objetivo encontrar alguma inibição no crescimento micelial de isolados de Candida albicans, Microsporum gyparum e Trichophyton rubrum, fornecidos pelo Laboratório de Micologia Médica da Universidade Estadual de Feira de Santana.

\section{Teste de difusão: perfuração em Agar}

$\mathrm{Na}$ técnica de perfuração em ágar, a remoção do meio de cultura sólido (Sabouraud) foi realizada com auxílio de cilindros de $6 \mathrm{~mm}$ de diâmetro para a formação de poços, nos quais seguida injetouse $20 \mu \mathrm{L}$ do extrato e incubou a placa a uma temperatura adequada $\left(28^{\circ} \mathrm{C}\right)$. Além do extrato bruto, na mesma placa colocou-se mais dois poços, um com água destilada e outro com o solvente utilizado para ressuspender o extrato (no caso, o acetato de etila).

\section{Bioautografia direta}

Inicialmente, foi realizada uma análise do extrato bruto por cromatografia em camada delgada (CCD), onde foram pipetadas $5 \mu \mathrm{L}$ das amostras colocadas em placas de sílicagel Whatman (SiO2 x H2O 20; 20 cm; G 60
F250nm). As placas foram imersa em solução de (Hexano / Acetato de Etila, 30\% / 70\%, v/v) que atuou como fase móvel. A revelação foi feita sob luz ultravioleta visualizando as manchas dos eluentes cromatográficos dos compostos dos extratos e calculou-se o fator de retardamento (Rf). Em seguida, as placas de CCD foram submetidos ao ensaio de bioautografia em uma fina camada de meio de cultura sabouroud e $10 \mu \mathrm{L}$ da solução de suspensão do microrganismo. Após a incubação, observou-se a formação dos halos de inibição. Para controle utilizou-se placa de sílica-gel nas mesmas condições empregadas no bioensaio, porém sem aplicação de amostra. A bioautografia direta foi realizada em duplicata.

\section{RESULTADOS E DISCUSSÃO}

Obteve-se, através do método de semeadura em placa de ágar, uma série de culturas puras em meio de cultura, resultando em um total de 45 bactérias, 3 leveduras e 35 fungos. Mas, dentre os microorganismos, destaca-se as bactérias devido à ocorrência de enorme variedade de tipos nutritivos e fisiológicos (versatilidade metabólica), excedendo a população de todos os outros grupos de microorganismos, tanto em número quanto em variedade.

A partir da cultura pura, realizou-se uma triagem das linhagens bacterianas, utilizando os extratos obtidos a partir da cultura líquida. Dentre essas linhagens, a 
rizobactéria 73 obteve grande interesse devido à ação frente aos patógenos utilizados no teste (Candida albicans, Microsporum gyparum e Trichophyton rubrum).

Em seguida, procedeu-se a caracterização da bactéria 73, foram realizadas observações macroscópicas, microscópicas e bioquímica (conforme Quadro 01). Vale ressaltar que utilizando a chave dicotômica da ordem das Eubacteriales, adaptada da $7^{\text {a }}$ edição de Bergey’s, verifica-se que a linhagem bacteriana não identificada pode ser incluída no grupo das Bacillaceae, e devido a formação de endósporos, essas linhagens foram identificadas do gênero Bacillus.

Quadro 01: Características macroscópicas, microscópicas e bioquímica da rizobactéria.

\begin{tabular}{|l|l|}
\hline Cor & Branca \\
\hline Superfície & Opaca \\
\hline Densidade & Opaca \\
\hline Consistência & Membranosa \\
\hline Forma & Irregular \\
\hline Margem & Ondulada \\
\hline Elevação & Elevada \\
\hline Forma & Bacilos \\
\hline Comprimento & Longos \\
\hline Largura & Grossos \\
\hline Presença de endósporos & Presente \\
\hline Coloração de Gram & Positivo \\
\hline Catalase & Negativo \\
\hline Citocromo - oxidase & Negativo \\
\hline
\end{tabular}

Fonte: O próprio autor

Devido a incerteza na identificação, foi realizado uma análise do eletroforetrograma de cada seqüência gerado no seqüenciador automático ABI377, após a busca de similaridade no banco de dados do GenBank através do programa BLASTn, a rizobactéria 73 foi identificada como Bacillus cereus $(\mathrm{MRbS} 26)$.

A linhagem identificada como Bacillus cereus foi submetido ao crescimento líquido em uma cultura líquida. Depois do tempo de incubação no agitador tipo shaker, obteve-se uma coloração amarelo-escura , representando o aumento do número bacteriano e dos metabólitos secundários originados. Realizouse uma extração líquido-líquido utilizando como solvente orgânico selecionado (acetato de etila) anteriormente devido ao seu ótimo desempenho na avaliação da atividade fúngica indicando uma maior eficiência na extração dos compostos antifúngicos frente aos patógenos testados.

Com o extrato bruto obtido, foram realizados testes de inibição para Candida albicans, Microsporum gyparum e Trichophyton rubrum. Observou-se uma ação inibitória discreta frente aos dois últimos patógenos (Microsporum gyparum e Trichophyton rubrum). Entretanto, observouse uma ação inibitória bastante considerável frente à Candida albicans, verificou-se que o halo de inibição do extrato obtido do isolado de Bacillus cereus é de 26,0 mm. È importante salientar que o solvente orgânico puro (acetato de etila) foi injetado em poço e não apresentou uma inibição visível, 
enfatizando o potencial inibitório da amostra de extrato utilizado.

Comparando com outros extratos, observa-se que o halo de inibição do extrato obtido do isolado de Bacillus cereus frente à Candida albicans é muito significativo. AMANCIO et al. (2015) avaliou a ação dos extratos de araçazeiro verde, araçazeiro seco, goiabeira verde e goiabeira seco sobre Candida albicans, obtendo um diâmetro máximo dos halos de inibição de $16 \mathrm{~mm}$.

Na literatura, observa-se que o gênero Bacillus apresenta grande potencial de uso no controle biológico de diversos patógenos. Vieira-Júnior (2005) verificou que os extratos obtidos por uma linhagem de Bacillus cereus foi capaz de inibir o crescimento micelial de diversos patógenos testados. Paz (2010) verificou um efeito fungistático de nove isolados de Bacillus na cultura do mamoeiro. Lima et al. (2014) afirmou que isolados de Bacillus apresentaram potencial para inibição do crescimento micelial de F. oxysporum.

Em seguida, foi realizada a análise do extrato bruto por cromatografia em camada delgada. A revelação foi feita sob luz ultravioleta visualizando as manchas dos eluentes cromatográficos dos compostos dos extratos. Observou-se a presença de três frações em uma placa de CCD de 7,0 x 2,0 cm (Figura 1).
Figura 01: Visualização da placa de CCD na câmara de luz ultravioleta

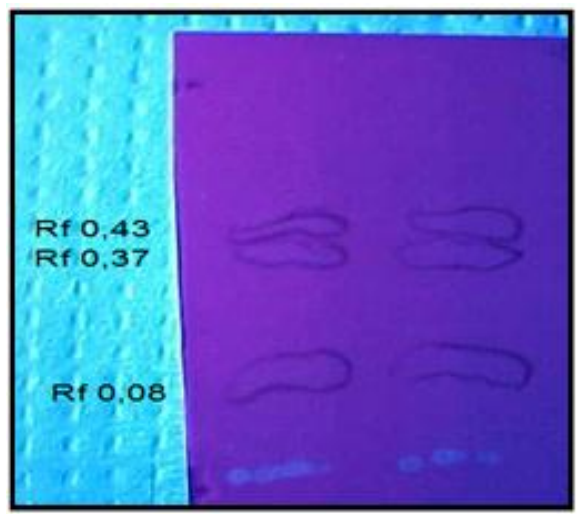

Fonte: O próprio autor

Por fim, após o período de incubação dos testes de bioautografia, observou-se a formação do halo de inibição na fração cujo fator de retardamento (Rf) é 0,43, identificando-a como a fração responsável pelo potencial inibitório frente ao patógeno testado (Candida albicans). Os resultados desse experimento dão indícios de que os isolados Bacillus cereus podem ser considerados fonte promissora de uma alternativa terapêutica para as infecções fúngicas, em especial a candidíase.

\section{CONCLUSÃO}

Com os resultados pode-se concluir que o Bacillus cereus (MRbS26) apresenta metabólitos secundários com potencial antifúngico e podem ser considerados fonte promissora de bioprospecção de novos fármacos. Tornando-se uma alternativa terapêutica, propiciando a síntese de um novo fármaco para $\mathrm{o}$ tratamento de infecções fúngicas, principalmente a candidíase. Deve salientar que devido a uma elevada incidência 
da candidíase e agravada pelo aumento de resistência aos medicamentos amplamente utilizado na terapia antifúngica, deve-se buscar novos fármacos como alternativas terapêuticas para esta patologia.

Neste contexto, observou-se uma atividade inibitória significativa dos extratos frente à Candida albicans, que através da bioautografia, visualizou-se que fração (Rf $0,43)$ é a fração que obteve maior eficiência na inibição do patógeno. Porém, é necessária a realização de estudos mais minuciosos, principalmente objetivando a purificação de compostos químicos presente na fração responsável pela ação, para alcançar maior eficiência frente ao patógeno. Além disso, deve-se avaliar a viabilidade técnica e econômica de uma possível síntese de um fármaco com grande potencial frente à Candida albicans.

\section{REFERÊNCIAS}

AMANCIO, A.M. et al. Estudo da ação antimicrobiana de extratos de plantas do gênero psydium. Revista da Universidade Vale do Rio Verde, Três Corações, v. 13, n. 1, p. 644-652, 2015

AUER C.G.; BETTIOL W. Efeito da serapilheira de Eucalyptus grandis no crescimento micelial de Pisolithus tinctorius em meio de cultura. IPEF, 1986.

CAMPOS SILVA, J.R. et al. Bactérias endofíticas no controle e inibição in vitro de Pseudomonas syringae pv. tomato, agente da pinta bacteriana do tomateiro. Ciência e Agrotecnologia, v.32, p.1062-1072, 2008.
CECHINEL FILHO, V, et al. R. A. Síntese de $\mathrm{N}$-alquilfenilmaleimidas e $\mathrm{N}$ alquilarilmaleimidas com atividade antifúngica. Quím. Nova, São Paulo: v.19, p. 590, 1996.

CELOTTO, A.C. et al. Evaluation of the in vitro antimicrobial activity of crude extracts of three Miconia species. Braz. J. Microbiol. n.4,v.34, p.339-340, 2003.

FAVEL, A. et al. In Vitro Antifungal activity of triterpenoid saponins. Planta Med.,

Stuttgart, v. 60, p. 50-53, 1994.

FERREIRA, P. H. C. Avaliação da atividade antifúngica do Rosmarinus officinalis frente à Candida albicans. Brazilian Journal of Health, v. 3, n. 1, p. 13-23, 2012.

KHAN, R. et al. Antimicrobial Activity Of Fiver Herbal Extracts Against Muiti Drug Resistant (MRD) Strains Of Bacteria And Fungus Of Clinical Origin. Molecules, v.14, n.2, p.586-597, 2009.

KIRAZ, N.U.; YASEMIN, O.Z. A distribuição das espécies e suscetibilidade in vitro de isolados clínicos de Candida de um hospital universitário na Turquia ao longo de um período de 5 anos. Medical Mycology, v.49, n.2, p.126-131, 2011.

LANNA FILHO, R.; FERRO, H.M.; PINHO, R.S.C. Controle biológico mediado por Bacillus subtilis. Revista Trópica Ciências Agrárias e Biológicas, V. 4, N. 2, p. 14, 2010.

LIMA, I.O. et al. Atividade antifúngica de óleos essenciais sobre espécies de Candida. Revista Brasileira de Farmacognosia, v.16, n.2, p.197-201, 2006.

LIMA, O.D.R. et al. Ação antifúngica in vitro de isolados de Bacillu ssp. sobre Fusarium oxysporum f. sp. Lycopersici. Revista Caatinga, Mossoró, v. 27, n. 4, p. 57- 64, dez., 2014. 
MELO, F. M. P. Atividade antifúngica de metabólitos secundários produzidos pelo endófito de mandioca Bacilus pumilus MAIIIM4a. 2005. 84 f. Dissertação (Mestrado em Agronomia) - Escola Su-perior de Agricultura "Luiz de Queiroz",

Universida-de de São Paulo, Piracicaba, 2005.

NAKAMURA, S. et al. Steroidal Saponins and Pseudoalkaloid Oligoglycoside from Brazilian 22 Natural Medicine, "Fruta do Lobo" (fruit of Solanum lycocarpum).

Phytochemistry, v.69, n.1, p.1565-1572, 2008.

NARDIN M.E.; PELEGRI D.G.; MANIAS V.G. Etiological agents of dermatomycoses isolated in a hospital of Santa Fé City, Argentina. Rev Argent Microbiol, n. 38, p. 25-27, 2006.

NEWMAN, D.J.; CRAGG, G.M. Natural products as source of new drugs over the last 25 years. Journal of Natural Products, V. 70, p. 461-477, 2007.

PERRY, N. B., FOSTER, L. M. Antiviral and Antifungal flavonoids, plus a triterpene, from Hebe cupressoides. Planta Med., Stuttgart, v. 60, p. 491-492, 1994.

PAZ, D. S. da. Ação inibitória de extratos vegetais, óleo de nim, produtos abiticos e Bacillus sobre Corynespora casiicola, agente da mancha-alvo do mamoeiro. 2010. 64 f. Dissertação (Mestrado em Agroecologia) - Universidade Estadual do Mara-nhão, São Luís, 2010.

PINTO T.J.A., KANEKO T.M., OHARA M.T. Controle Biológico de Qualidade de Produtos Farmacêuticos, Correlatos e Cosméticos. 2.ed. São Paulo: Atheneu Editora, 325 p, 2003.

RAMASAMY K. et al. Antimicrobial and cytotoxic activities of Malaysian endophytes. Phytother Res, n. 24, p. 640-643, 2010.
Colletotrichum gloeosporioides Penz. isolado do maracujazeiro. Ciência e Agrotecnologia, v. 33, p. 1853 -1860, 2009.

STARGARLIN J.R. et al. Plantas medicinais e controle alternativo de fitopatógenos.

Biotecnologia Ciência \& Desenvolvimento, v. 11, 1999. p.6-21.

TAKAHASHI, J.; LUCAS, E.M.F. Ocorrência e diversidade estrutural de metabólitos fúngicos com atividade antibiótica. Quím. Nova. V. 31. N. 7, p. 1807-1813, 2008.

\section{VIEIRA JUNIOR, J. R. Procariotas} residentes do filoplano do feijoeiro como agentes de biocontrole de enfermidades da parte aérea da cultura. 2005. 146 f. Tese (Doutorado em Fitopatologia), Universidade Federal de Viçosa, Viçosa, 2005.

XUE, H. et al. Secondary metabolites of Aspergillus sp. CM9a, an endophytic fungus of Cephalotaxus mannii. Rec Nat Prod. v. 6. n.1 p. 28-34, 2012.

SILVA, A.C et al. Efeito in vitro de compostos de plantas sobre o fungo 